\title{
Changes in Cerebral Oxygen Consumption and High-Energy Phosphates During Early Recovery in Hypoxic-Ischemic Piglets: A Combined Near-Infrared and Magnetic Resonance Spectroscopy Study
}

\author{
JEFF D. WINTER, KENNETH M. TICHAUER, NEIL GELMAN, R. TERRY THOMPSON, TING-YIM LEE, \\ AND KEITH ST. LAWRENCE
}

\begin{abstract}
Imaging Division [J.D.W., K.M.T, N.G., R.T.T., T.-Y.L., K.S.L.], Lawson Health Research Institute, London, Ontario, N6A 4V2, Canada; Department of Medical Biophysics [J.D.W., K.M.T., N.G., R.T.T., T.-Y.L., K.S.L.], University of Western Ontario, London, Ontario, N6A 5B8, Canada; and Imaging [T.-Y.L.], Robarts Research Institute, London, Ontario, N6A 5B8, Canada
\end{abstract}

\begin{abstract}
Near-infrared spectroscopy (NIRS) offers the ability to assess brain function at the bedside of critically ill neonates. Our group previously demonstrated a persistent reduction in the cerebral metabolic rate of oxygen $\left(\mathrm{CMRO}_{2}\right)$ after hypoxia-ischemia (HI) in newborn piglets. The purpose of this current study was to determine the causes of this reduction by combining NIRS with magnetic resonance spectroscopy (MRS) to measure high-energy metabolites and diffusion-weighted imaging to measure cellular edema. Nine piglets were exposed to $30 \mathrm{~min}$ of $\mathrm{HI}$ and nine piglets served as controls. Proton and phosphorous MRS spectra, apparent diffusion coefficient $(\mathrm{ADC})$ maps, and $\mathrm{CMRO}_{2}$ measurements were collected periodically before and for $5.5 \mathrm{~h}$ after HI. A significant decrease in $\mathrm{CMRO}_{2}(26 \pm 7 \%)$ was observed after HI. Incomplete recovery of nucleotide triphosphate concentration $(8 \pm 3 \%<$ controls $)$ and reduced ADC $(16 \pm 5 \%)$ suggested mitochondrial dysfunction. However, $\mathrm{CMRO}_{2}$ did not correlate with any metabolite concentration during the last $3 \mathrm{~h}$ of the recovery period, and no significant changes were found in phosphocreatine and lactate levels. Therefore, the $\mathrm{CMRO}_{2}$ decrease is likely a combination of impaired mitochondrial function and reduced energy demands during the acute phase, which has been previously observed in the mature brain. (Pediatr Res 65: 181-187, 2009)
\end{abstract}

$\mathrm{P}$ erinatal hypoxia-ischemia (HI) is a major cause of neurologic injury in newborns, affecting one to six of every 1000 live term births (1). Evidence suggests that a significant proportion of brain injury manifests 1 to $3 \mathrm{~d}$ after the hypoxicischemic insult (2). The delay between insult and injury has given rise to the concept that there exists a brief period after HI when it may be possible to minimize tissue damage by interrupting the processes contributing to delayed neuronal death (2). Potential neuroprotective therapies include mild hypothermia, inhibitors of free radical production, and free radical scavengers $(3,4)$. However, the efficacy of such therapies depends, in part, on early detection of the onset of delayed brain injury.

Received May 12, 2008; accepted August 20, 2008

Correspondence: Keith St. Lawrence, Ph.D., Department of Nuclear Medicine, St. Joseph's Health Centre, 268 Grosvenor Street, London, Ontario, Canada, N6A 4V2; e-mail: kstlaw@lawsonimaging.ca

Supported by the Canadian Institute for Health Research, Multi-Magnetics Inc., and the Ontario Research and Development Challenge Fund.
Key to understanding the progression of brain injury after $\mathrm{HI}$ is the concept of secondary energy failure. Phosphorous magnetic resonance spectroscopy $\left({ }^{31} \mathrm{P}-\mathrm{MRS}\right)$ studies found that the ratio of phosphocreatine ( $\mathrm{PCr}$ ) to inorganic phosphate (Pi) was normal soon after birth in infants with clinical symptoms of birth asphyxia, but progressively declined over the following days (5). Furthermore, the minimum $\mathrm{PCr} / \mathrm{Pi}$ during secondary energy failure or, correspondingly, the maximum increase in the lactate (Lac) signal measured by proton magnetic resonance spectroscopy ( $\left.{ }^{1} \mathrm{H}-\mathrm{MRS}\right)$ strongly correlated with neurodevelopmental impairment at 1 and 4 years of age $(6,7)$. The occurrence of secondary energy failure observed clinically has been replicated in animal models of perinatal $\mathrm{HI}$, including piglets $(8,9)$ and rat pups $(10)$.

The near complete recovery of high-energy phosphates during the early recovery phase observed in animal ${ }^{31} \mathrm{P}-\mathrm{MRS}$ studies does not necessarily imply restoration of normal mitochondrial respiratory function. Evidence of early mitochondrial impairment includes elevated Lac (9), increased glucose consumption (11), and depressed mitochondrial respiration (12). These occur despite the return of cerebral blood flow (CBF) and blood oxygenation to preHI levels. Together, these studies suggest that a measure of oxidative metabolism may be an earlier indicator of $\mathrm{HI}$ before secondary energy failure observed by MRS (13).

Our group developed and validated a method for determining the cerebral metabolic rate of oxygen $\left(\mathrm{CMRO}_{2}\right)$ using near-infrared spectroscopy (NIRS) measurements of cerebral hemodyamics and deoxyhemoglobin $(\mathrm{Hb})(14,15)$. A persistent reduction in $\mathrm{CMRO}_{2}$ (25\% compared with controls) after HI was observed in piglets (16). These results, coupled with

\footnotetext{
Abbreviations: ${ }^{1} \mathbf{H}-\mathrm{MRS}$, proton magnetic resonance spectroscopy; ${ }^{31} \mathbf{P}-\mathbf{M R S}$, phosphorous magnetic resonance spectroscopy; ADC, apparent diffusion coefficient; CBF, cerebral blood flow; CBV, cerebral blood volume; Cho, choline; $\mathrm{CMRO}_{2}$, cerebral metabolic rate of oxygen; $\mathbf{C u}_{\mathrm{A}}$, copper A centre of cytochrome oxidase; DW, diffusion-weighted imaging; EPP, total exchangeable phosphate pool; Hb, deoxyhemoglobin; HI, hypoxia-ischemia; Lac, lactate; NIRS, nearinfrared spectroscopy; NTP, nucleotide triphosphate; $\mathbf{P C r}$, phosphocreatine; $\mathbf{p H}_{\mathbf{i}}$, intracellular $\mathrm{pH} ; \mathbf{P}_{\mathbf{i}}$, inorganic phosphate
} 
recent studies using NIRS to measure $\mathrm{CMRO}_{2}$ in neonates (17), indicate that $\mathrm{CMRO}_{2}$ may be a clinically viable early marker of HI. In this study, possible causes of reduced oxidative metabolism were investigated to better understand the diagnostic value of $\mathrm{CMRO}_{2}$. Simultaneous changes in $\mathrm{CMRO}_{2}$ and high-energy metabolites were measured by combining NIRS and MRS, and cellular edema was assessed by diffusion-weighted (DW) MRI. Combining these techniques allowed us to determine the relative contributions of impaired oxidative metabolism and reduced cerebral energy demand to the $\mathrm{CMRO}_{2}$ decreases measured in the postHI brain. Both possibilities have been reported in other models of transient global ischemia, depending on the duration of ischemia (18).

\section{METHODS}

Animal preparation. The Council on Animal Care at the University of Western Ontario approved this study. Duroc piglets were anesthetized with $1.5-1.75 \%$ isoflurane (3\% during surgery), tracheotomized, and mechanically ventilated on an oxygen/medical air mixture. Two incisions were made lateral to the trachea, and vascular occluders $(1.5 \mathrm{~mm}$ inner diameter) were placed around both carotid arteries proximal to the carotid bifurcation (In Vivo Metric, Healdsberg, CA). A catheter was inserted into an ear vein or an abdominal vein for injecting the NIRS-sensitive contrast agent, indocyanine green. A catheter was also placed into a femoral artery to monitor blood pressure and to collect arterial blood samples. All incisions were treated with a topical anesthetic (marcaine). Piglets were allowed to stabilize for $1 \mathrm{~h}$ before baseline measurements.

Experimental procedures. Piglets were randomly divided into two groups before surgery: a HI group (nine piglets, mean age $16 \pm 3 \mathrm{~h}$ and mean weight $1.61 \pm 0.07 \mathrm{~kg}$ ) and a sham-operated control group (nine piglets, mean age $14 \pm 2 \mathrm{~h}$ and mean weight $1.54 \pm 0.06 \mathrm{~kg}$ ). After baseline measurements, HI was induced by inflating the vascular occluders and reducing the fraction of inspired oxygen to $7 \%$ to cause systemic hypoxia. Occluders were released and inspired oxygen was returned to baseline levels after $30 \mathrm{~min}$.

Collection times for the NIRS-CMRO ${ }_{2}$ measurements, ${ }^{31} \mathrm{P}-\mathrm{MRS}$ and ${ }^{1} \mathrm{H}$-MRS spectra, and diffusion-weighted imaging (DWI) are provided in Figure 1. Throughout the experiment (excluding the insult), arterial $\mathrm{CO}_{2}$ tension was maintained within $35-45 \mathrm{~mm} \mathrm{Hg}$, and arterial $\mathrm{O}_{2}$ tension was maintained within 120-250 mm Hg. Blood glucose was kept above $3 \mathrm{mM}$ and rectal temperature was maintained between 37.5 and $38.5^{\circ} \mathrm{C}$. Arterial $\mathrm{pH}$ and heart rate were monitored throughout the experiment.

Near-infrared spectroscopy. The NIRS data were collected with a continuous-wave, broadband system. Near-infrared light from a tungsten lightsource (filtered to $600-980 \mathrm{~nm}$ ) was delivered to the head of the piglets via a single fiber-optic bundle. A second fiber-optic bundle, placed $3 \mathrm{~cm}$ parasagittally to the first bundle, collected transmitted NIR light for spectrometric analysis.

As previously outlined (15), NIRS measurements of $\mathrm{CMRO}_{2}$ were based on the Fick principle:

$$
\mathrm{CMRO}_{2}=\mathrm{CBF}\left(\left[\mathrm{O}_{2}\right]_{\mathrm{a}}-\left[\mathrm{O}_{2}\right]_{\mathrm{v}}\right)
$$

The arterial oxygen concentration, $\left[\mathrm{O}_{2}\right]_{\mathrm{a}}$, was determined using a pulseoximeter placed on the hind foot of the piglet. The cerebral venous oxygen concentration, $\left[\mathrm{O}_{2}\right]_{\mathrm{v}}$, was determined from NIRS measurements of the cerebral $[\mathrm{Hb}]$, which were quantified using the second-derivative technique (19).

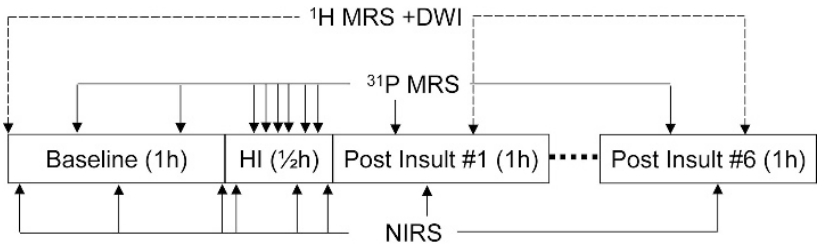

Figure 1. Experimental timing diagram. HI refers to the $30 \mathrm{~min}$ hypoxicischemic insult. ${ }^{31} \mathrm{P}$ MRS averaged over $20 \mathrm{~min}$ during baseline, $3.33 \mathrm{~min}$ during HI, and 20 min during the postinsult period. Only the first hour after $\mathrm{HI}$ is shown since the timings of the measurements were the same in all subsequent hours.
The venous $[\mathrm{Hb}]$ was calculated by normalizing NIRS $[\mathrm{Hb}]$ measurements to the cerebral blood volume (CBV) and assuming the blood volume was comprised of $25 \%$ arterial and $75 \%$ venous blood (20). Cerebral blood flow and CBV were determined by tracking a bolus injection of indocyanine green (14). With this method, the tissue concentration of indocyanine green, $Q(t)$, is related to the arterial blood concentration, $\mathrm{C}_{\mathrm{a}}(\mathrm{t})$, by (14):

$$
Q(t)=C B F \cdot C_{\mathrm{a}}(t) * R(t)
$$

The symbol * refers to the convolution operator, $\mathrm{R}(\mathrm{t})$ is the impulse residue function, Q(t) was determined from NIR spectra acquired at $200 \mathrm{~ms}$ intervals, and $\mathrm{C}_{\mathrm{a}}(\mathrm{t})$ from a dye densitogram unit (DDG-2001 A/K, Nihon Kohden, Tokyo, Japan) attached to the hind foot. Deconvolution was used to solve for the product $\mathrm{CBF} \cdot \mathrm{R}(\mathrm{t})$, in which the initial height equals $\mathrm{CBF}$ and the area under the function equals CBV.

Magnetic resonance spectroscopy. The MRS data were collected on a 3.0 $\mathrm{T}$ scanner controlled by a SMIS console (Surrey Medical Imaging System Ltd., UK). Phosphorous radio frequency transmission and detection were achieved using a $25 \mathrm{~mm}$ diameter surface coil placed on the scalp between the two NIRS probes. Phosphorous data were acquired with a pulse-acquire sequence using a $90^{\circ}$ adiabatic excitation pulse ( $3 \mathrm{~ms}$ duration). The acquisition parameters were as follows: $5 \mathrm{kHz}$ spectral width, $10 \mathrm{~s}$ repetition time, 2048 complex data points, 120 averages during baseline and post insult, and 20 averages during HI. Spectra were left-shifted 5 points $(1 \mathrm{~ms})$ to eliminate membrane and bone contributions and fit in the time domain using prior knowledge spectral information, obtained from in vitro solutions of individual metabolites, with a constrained Levenberg-Marquardt minimization algorithm (21).

Concentrations of $\mathrm{PCr}$ and $\mathrm{Pi}$ were obtained from their respective peaks. In general, the Pi peak was fit with a single component. If necessary, two components were used to fit spectra during the insult and at the first postHI time point. The concentration of nucleotide triphosphate [NTP], was determined from the $\beta$-NTP peak. To compare baseline values between groups, [PCr] was expressed as a fraction of [Pi] and [NTP] was expressed as a fraction of the concentration of total exchangeable phosphate pool ([EPP]), where $[\mathrm{EPP}]=[\mathrm{Pi}]+[\mathrm{PCr}]+[(\gamma+\alpha+\beta) \mathrm{NTP}]$. To assess the affects of $\mathrm{HI}$ on the individual metabolites, each metabolite signal was normalized to its baseline value and compared with the normalized value from the control group. The normalized [EPP] signal was used to investigate possible signal changes independent of $\mathrm{HI}$, such as a change in coil loading. Intracellular $\mathrm{pH}$ $\left(\mathrm{pH}_{\mathrm{i}}\right)$ was determined by the chemical shift between the Pi and PCr peaks using the Henderson-Hasselbalch equation (8).

Proton radio frequency transmission and detection were achieved using a custom-built quadrature birdcage coil (XL Resonance, London, Canada) with an inner diameter of $20 \mathrm{~cm}$. Proton spectra were localized using a pointresolved spectroscopy sequence (PRESS) with an echo time of $135 \mathrm{~ms}$ to invert the Lac peak. Water suppression was achieved using three chemical shift selective pulses. Spectra were collected from a voxel $(1.7-2.7 \mathrm{~mL})$ in deep gray matter. This region was chosen to avoid large magnetic susceptibility artifacts from the ${ }^{31} \mathrm{P}$ surface coil and because it is known to be sensitive to HI. The ${ }^{1} \mathrm{H}-\mathrm{MRS}$ acquisition parameters were as follows: $2 \mathrm{kHz}$ spectral width, 2 s repetition time, 2048 complex data points, and 128 watersuppressed and 16 unsuppressed signal averages. Residual water signal was fit with a Hankel singular value decomposition algorithm and subtracted from the spectra. Water-suppressed and line shape-corrected ${ }^{1} \mathrm{H}$ spectra were fit in the time domain using prior knowledge (22) to extract the Lac-to-choline (Cho) ratio.

Diffusion-weighted imaging. Imaging was performed using a segmented echo-planar imaging sequence with velocity-compensated diffusion gradients $\left(b=600 \mathrm{~s} / \mathrm{mm}^{2}\right)$. Ten imaging volumes were acquired: nine with different directional DW and one without DW. Imaging parameters were as follows: six-segments, spin echo, $160 \mathrm{~mm}$ field-of-view, $4 \mathrm{~mm}$ slice thickness, 10 slices, $96 \times 96$ matrix size, and $140 \mathrm{~ms}$ echo time. Apparent diffusion coefficient (ADC) maps were generated after computing the eigenvalues and eigenvectors of the diffusion tensor. Mean ADC values were measured in deep gray matter regions similar to where the ${ }^{1} \mathrm{H}-\mathrm{MRS}$ spectra were acquired.

Statistical analysis. Within- and between-subject group interactions for all data at baseline and post HI were determined by a two-way, repeatedmeasures ANOVA. If a significant interaction was found, the source of the interaction was determined using a one-way ANOVA with a Bonferroni adjustment for multiple comparisons. The relationship between $\mathrm{CMRO}_{2}$ and each of the MRS/MRI parameters ([PCr], [Pi], [NTP], [Lac]/[Cho], ADC) within the HI group was investigated by linear regression using the average values for the last $3 \mathrm{~h}$ postinsult. Results were considered statistically significant for $p<0.05$. All statistical analyses were performed using SPSS v15.0 (SPSS Inc., Chicago, IL). All results are displayed as mean \pm SE. 


\section{RESULTS}

Table 1 summarizes the physiologic parameters for control and HI piglets. Baseline data are presented along with average values for the first (post1), second (post2), and third (post3) 2-h blocks of the recovery period. No significant inter-group differences were observed for any of the physiologic parameters at any time point. Although a trend of elevated heart rate in both groups was observed, all values remained within the normal physiologic range. A nonsignificant increase in $\mathrm{O}_{2}$ tension in controls was also observed; however, this had negligible effects as evident by the agreement in baseline CBF values between groups (Table 2). Mean body temperature (mean $\pm \mathrm{SD}$ ) was $38.0 \pm 0.2$ and $37.9 \pm 0.1^{\circ} \mathrm{C}$ for the control and $\mathrm{HI}$ group, respectively. Table 2 summarizes the baseline measurements of $\mathrm{CBF}, \mathrm{CBV},[\mathrm{Hb}], \mathrm{CMRO}_{2},[\mathrm{PCr}] /[\mathrm{Pi}]$, $[\mathrm{NTP}] /[\mathrm{EPP}], \mathrm{pH}_{\mathrm{i}}$, [Lac]/[Cho], and ADC. Only $\mathrm{pH}_{\mathrm{i}}$ demonstrated a significant difference between groups. Immediately before reperfusion, $\mathrm{CBF}$ decreased to $4.1 \pm 1.7 \mathrm{~mL} / \mathrm{min} / 100 \mathrm{~g}$, $\mathrm{PCr} / \mathrm{Pi}$ to $0.019 \pm 0.013$ and NTP/EPP to $0.036 \pm 0.015$, all of which are similar to previous reports $(8,16)$.

All significant time-by-group interactions are summarized in Table 3. No significant inter-group differences were observed for $\mathrm{CBF}$ or $\mathrm{CBV}$ at any time point. Both $[\mathrm{Hb}]$ and

Table 1. Physiological parameters

\begin{tabular}{|c|c|c|c|c|}
\hline & Baseline & Post1 & Post2 & Post3 \\
\hline \multicolumn{5}{|c|}{ Arterial $\mathrm{CO}_{2}$ tension, $\mathrm{mm} \mathrm{Hg}$} \\
\hline HI & $39.6 \pm 1.4$ & $40.1 \pm 1.6$ & $38.8 \pm 1.5$ & $40.0 \pm 2.0$ \\
\hline Control & $42.5 \pm 1.5$ & $38.7 \pm 2.1$ & $41.7 \pm 1.6$ & $41.3 \pm 2.1$ \\
\hline \multicolumn{5}{|c|}{ Mean arterial pressure, $\mathrm{mm} \mathrm{Hg}$} \\
\hline $\mathrm{HI}$ & $43.9 \pm 1.9$ & $45.0 \pm 1.6$ & $42.3 \pm 2.2$ & $41.5 \pm 2.4$ \\
\hline Control & $44.8 \pm 2.0$ & $42.5 \pm 1.8$ & $38.5 \pm 2.3$ & $38.2 \pm 2.5$ \\
\hline \multicolumn{5}{|l|}{$\mathrm{pH}_{\mathrm{a}}$} \\
\hline $\mathrm{HI}$ & $7.43 \pm 0.03$ & $7.32 \pm 0.02$ & $7.42 \pm 0.02$ & $7.44 \pm 0.03$ \\
\hline Control & $7.39 \pm 0.02$ & $7.39 \pm 0.02$ & $7.38 \pm 0.02$ & $7.36 \pm 0.03$ \\
\hline \multicolumn{5}{|c|}{ Glucose, $\mathrm{mM}$} \\
\hline $\mathrm{HI}$ & $5.90 \pm 0.72$ & $9.67 \pm 1.08$ & $7.99 \pm 1.22$ & $8.03 \pm 1.17$ \\
\hline Control & $6.07 \pm 0.76$ & $7.95 \pm 1.13$ & $7.98 \pm 1.28$ & $6.03 \pm 1.24$ \\
\hline \multicolumn{5}{|c|}{ Arterial $\mathrm{O}_{2}$ tension, $\mathrm{mm} \mathrm{Hg}$} \\
\hline $\mathrm{HI}$ & $132.3 \pm 18.7$ & $138.5 \pm 14.0$ & $127.5 \pm 14.2$ & $133.4 \pm 16.7$ \\
\hline Control & $164.5 \pm 19.8$ & $161.2 \pm 14.8$ & $177.1 \pm 15.0$ & $192.7 \pm 17.6$ \\
\hline \multicolumn{5}{|c|}{ Heart rate, beats/min } \\
\hline $\mathrm{HI}$ & $161.4 \pm 9.4$ & $200.3 \pm 10.9$ & $202.9 \pm 10.1$ & $198.2 \pm 8.5$ \\
\hline Control & $166.7 \pm 10.0$ & $193.6 \pm 11.4$ & $200.8 \pm 10.6$ & $202.2 \pm 9.0$ \\
\hline
\end{tabular}

Physiological parameters at baseline and the average of the first (post1), second (post2), and third (post3) 2-h blocks of the $6 \mathrm{~h}$ recovery period.

Table 2. Mean baseline measurements for HI and control groups

\begin{tabular}{lcc}
\hline \multicolumn{1}{c}{ Parameter } & HI group & Control group \\
\hline $\mathrm{CBF}(\mathrm{mL} / \mathrm{min} / 100 \mathrm{~g})$ & $47.0 \pm 2.5$ & $49.8 \pm 4.7$ \\
$\mathrm{CBV}(\mathrm{mL} / 100 \mathrm{~g})$ & $3.67 \pm 0.26$ & $3.95 \pm 0.13$ \\
{$[\mathrm{Hb}](\mu \mathrm{M})$} & $11.7 \pm 1.0$ & $13.3 \pm 1.0$ \\
$\mathrm{CMRO}_{2}(\mathrm{~mL}$ & $1.84 \pm 0.08$ & $1.93 \pm 0.10$ \\
$\left.\mathrm{O}_{2} / \mathrm{min} / 100 \mathrm{~g}\right)$ & & \\
{$[\mathrm{PCr}] /[\mathrm{Pi}]$} & $1.95 \pm 0.04$ & $1.90 \pm 0.04$ \\
{$[\mathrm{NTP}] /[\mathrm{EPP}]$} & $0.165 \pm 0.001$ & $0.165 \pm 0.003$ \\
{$[\mathrm{pH}]$} & $7.148 \pm 0.006^{*}$ & $7.121 \pm 0.007$ \\
{$[\mathrm{Lac}] /[\mathrm{Cho}]$} & $0.04 \pm 0.01$ & $0.06 \pm 0.01$ \\
$\mathrm{ADC}\left(\times 10^{-3} \mathrm{~mm}^{2} / \mathrm{s}\right)$ & $0.87 \pm 0.02$ & $0.86 \pm 0.02$ \\
\hline
\end{tabular}

$* p<0.001$
Table 3. Significant ANOVA time-by-group interactions

\begin{tabular}{lcll}
\hline \multicolumn{1}{c}{ Parameter } & \multicolumn{1}{c}{ ANOVA } & $p$ & Power \\
\hline$[\mathrm{Hb}](\mu \mathrm{M})$ & $\mathrm{F}(8,128)=2.93$ & $<0.01$ & $>0.90$ \\
$\mathrm{CMRO}_{2}(\mathrm{~mL}$ & $\mathrm{F}(8,128)=5.55$ & $<0.001$ & $>0.99$ \\
$\left.\mathrm{O}_{2} / \mathrm{min} / 100 \mathrm{~g}\right)$ & & & \\
{$[\mathrm{PCr}]$} & $\mathrm{F}(7,96)=31.20$ & $<0.001$ & $>0.99$ \\
{$[\mathrm{NTP}]$} & $\mathrm{F}(7,96)=31.20$ & $<0.001$ & $>0.99$ \\
{$[\mathrm{Pi}]$} & $\mathrm{F}(7,96)=11.86$ & $<0.001$ & $>0.99$ \\
{$[\mathrm{EPP}]$} & $\mathrm{F}(7,96)=2.90$ & $<0.01$ & $>0.80$ \\
{$[\mathrm{pH}]$} & $\mathrm{F}(7,96)=9.84$ & $<0.001$ & $>0.99$ \\
{$[\mathrm{Lac}] /[\mathrm{Cho}]$} & $\mathrm{F}(6,96)=16.49$ & $<0.001$ & $>0.99$ \\
$\mathrm{ADC}\left(\times 10^{-3} \mathrm{~mm}^{2} / \mathrm{s}\right)$ & $\mathrm{F}(6,96)=12.59$ & $<0.05$ & $>0.80$ \\
\hline
\end{tabular}

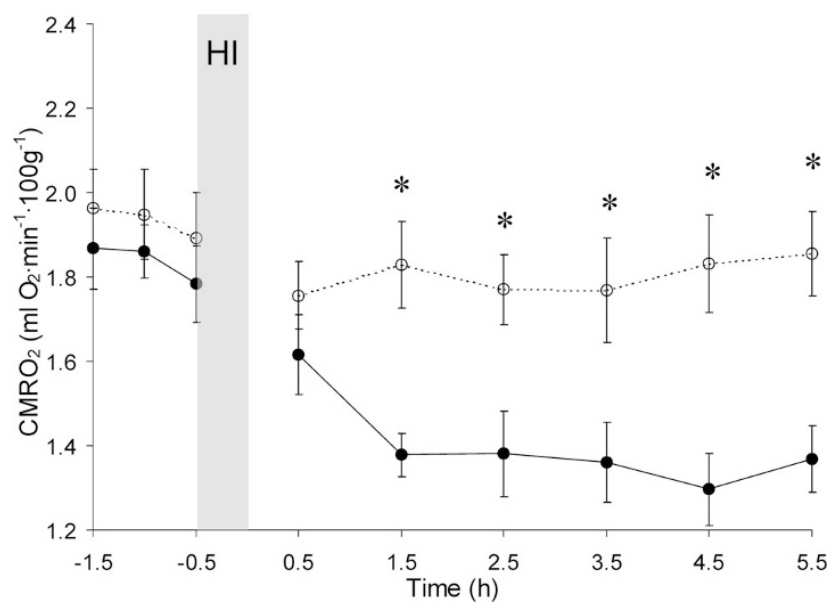

Figure 2. Time course of the cerebral metabolic rate of $\mathrm{O}_{2}\left(\mathrm{CMRO}_{2}\right)$. Average $\mathrm{CMRO}_{2}$ in the $\mathrm{HI}$ (solid line) and control (dotted line) groups. Gray area represents the $\mathrm{HI}$ insult. Error bars are SE. ${ }^{*} p<0.05$ between groups.

$\mathrm{CMRO}_{2}$ showed a significant decrease in the HI group at all postinsult times except at $1.5 \mathrm{~h}$ for $[\mathrm{Hb}]$ and at $0.5 \mathrm{~h}$ for $\mathrm{CMRO}_{2}$ (Fig. 2).

Figure 3 shows ${ }^{31} \mathrm{P}$-spectra from a representative piglet at baseline, and at 0.5 and $5.5 \mathrm{~h}$ postinsult. The metabolites levels for $[\mathrm{PCr}],[\mathrm{NTP}]$ and $[\mathrm{Pi}]$ in the HI group were all statistically significant at $0.5 \mathrm{~h}$ postinsult, followed by a general recovery to control levels (Fig. 4). A decrease in [NTP] was observed in the HI group at the last two recovery time points $(4.5$ and $5.5 \mathrm{~h})$ and $[\mathrm{Pi}]$ was elevated at the last time point. Included in Figure 4 is the time course of [EPP]. A significant time-by-group interaction was observed, although no significant group differences existed for individual time points. The lack of changes in the [EPP] time course at later time points indicates that possible causes of signal change independent of HI, e.g., coil-loading, were minimal. Tissue $\mathrm{pH}_{\mathrm{i}}$ was reduced in the $\mathrm{HI}$ group at $0.5 \mathrm{~h}$, followed by an elevation in this group at $1.5 \mathrm{~h}$.

The $[\mathrm{Lac}] /[\mathrm{Cho}]$ ratio was elevated in the HI group immediately after HI ( 0.5 and $1.5 \mathrm{~h})$; however, no differences existed between the two groups at later recovery time points (Fig. 5). Mean ADC values showed a time-by-group interaction because of significantly lower values for the HI group at all time-points after $2.5 \mathrm{~h}$ (Fig. 6).

The relationship between $\mathrm{CMRO}_{2}$ and each metabolite concentration is shown in Figure 7. All parameters were averaged over the last three time points; i.e., after general 

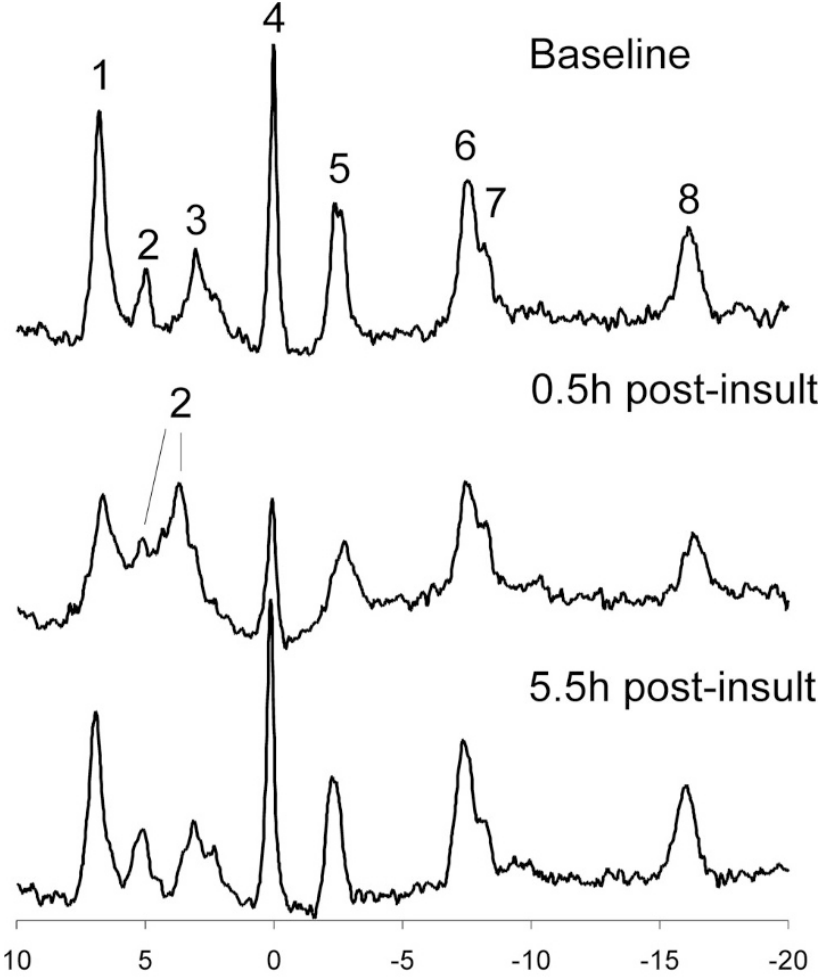

Chemical Shift (ppm)

Figure 3. Example spectra from one piglet in the HI group. Labels for the main metabolite resonances are as follows: 1 , phosphomonoesters; $2, \mathrm{Pi} ; 3$, phosphodiesters; 4, PCr; 5, $\gamma$-NTP; $6, \alpha$-NTP; 7, NAD and NADH; $8, \beta$-NTP. Spectra are displayed with $5 \mathrm{~Hz}$ exponential filtering.

recovery from HI. No significant correlations between $\mathrm{CMRO}_{2}$ and any of the metabolites were observed, nor was there a correlation between $\mathrm{CMRO}_{2}$ and ADC.

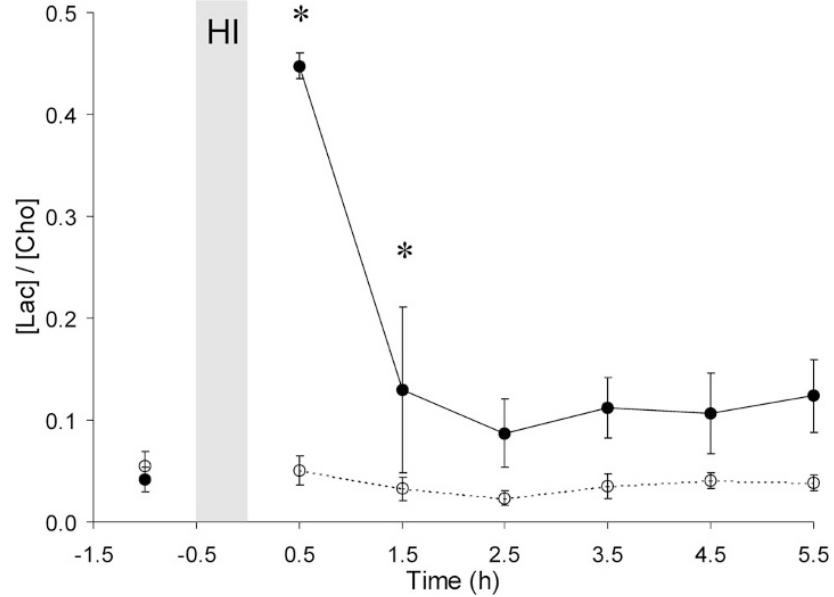

Figure 5. Time course of the ratio of $[\mathrm{Lac}] /[\mathrm{Cho}]$. Average metabolite ratio in the HI (solid line) and control (dotted line) groups. Gray area represents the $\mathrm{HI}$ insult. Error bars are SE. * $p<0.05$ between groups.

\section{DISCUSSION}

A number of studies have investigated the relationship between NIRS measurements of cerebral oxygenation and changes in high-energy metabolite concentrations (23-26). Combining NIRS and MRS, Cooper and Springett demonstrated good agreement between the time courses of the redox state of the copper A center of cytochrome oxidase $\left(\mathrm{Cu}_{\mathrm{A}}\right)$ and [NTP] during secondary energy failure (26). However, accuracy of the $\mathrm{Cu}_{\mathrm{A}}$ signal was adversely affected by changes in the optical path length. This observation, combined with the low sensitivity of $\mathrm{Cu}_{\mathrm{A}}$ and the potential contamination by $\mathrm{Hb}$ signals, speaks to the challenges of using $\mathrm{Cu}_{\mathrm{A}}$ as a clinical marker of $\mathrm{HI}$. Although the $\mathrm{Hb}$ signals have greater sensitivity than $\mathrm{Cu}_{\mathrm{A}}$, cerebral blood oxygenation is not a direct measure
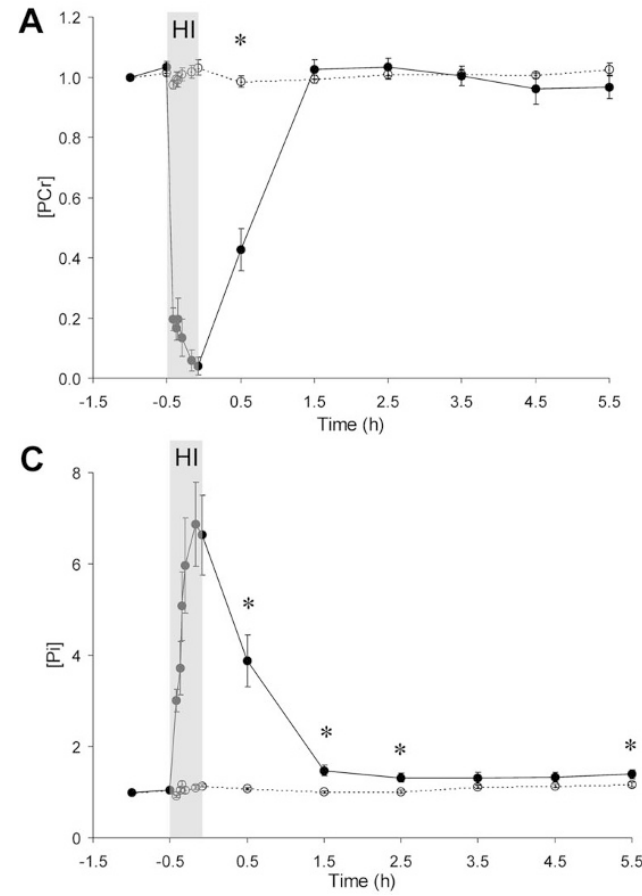
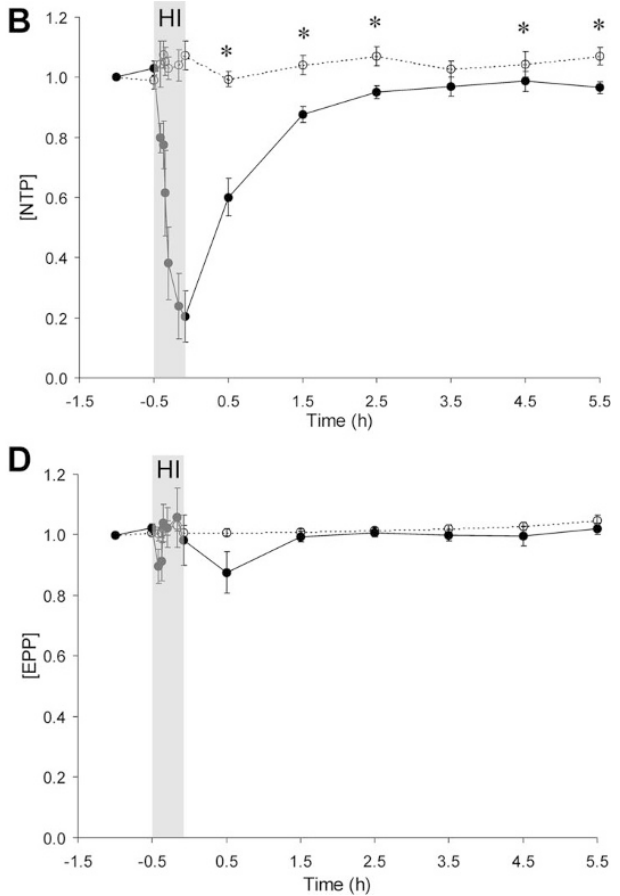

Figure 4. Time course of each phosphorous metabolite normalized to its first baseline value. Average metabolite level in the $\mathrm{HI}$ (solid line) and control (dotted line) groups. Gray area represents the HI insult. (A) $[\mathrm{PCr}] ;(B)[\mathrm{NTP}] ;(C)[\mathrm{Pi}]$; and $(D)$ [EPP]. Error bars are SE. * $p<0.05$ between groups. 


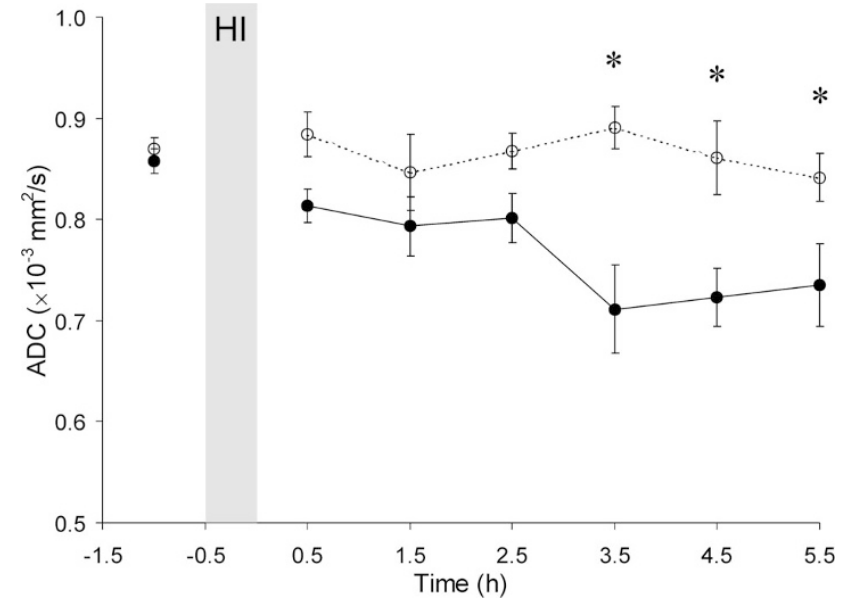

Figure 6. Time course of the ADC. Average ADC in the HI (solid line) and control (dotted line) groups. Gray area represents the $\mathrm{HI}$ insult. Error bars are SE. $* p<0.05$ between groups.

of metabolism, and these signals have been noticeably insensitive to other markers of brain injury $(23,25,27)$.

It is our assertion that NIRS measurements of $\mathrm{CMRO}_{2}$, derived, in part, from $[\mathrm{Hb}]$, could provide a clinically relevant means of assessing cerebral metabolism after HI. The present study aimed to better understand the causes of the $\mathrm{CMRO}_{2}$ changes using MRS/MRI to measure concurrent effects of $\mathrm{HI}$ on high-energy metabolites, lactate, and ADC. The NIRS data demonstrated a persistent reduction in $\mathrm{CMRO}_{2}$ after $30 \mathrm{~min}$ of $\mathrm{HI}$ in agreement with our previous study (16). Simultaneously collected ${ }^{31} \mathrm{P}$-MRS data showed a general recovery of the high-energy phosphates, although this recovery was not complete. Averaged over the last 3 time points and compared with controls, there was an $8 \pm 3 \%$ decrease in [NTP] $(p<0.05)$ and a $16 \pm 5 \%$ decrease in the ADC value $(p<$ 0.001). In the same timeframe, average [Pi] and [Lac]/
[Cho] were slightly elevated and $[\mathrm{PCr}]$ was slightly depressed as a result of HI; however, these differences did not reach statistical significance.

The observed reduction in $\mathrm{CMRO}_{2}$ during the early recovery period after $\mathrm{HI}$ could reflect impaired oxidative energy metabolism, reduced cerebral energy demand, or a combination of the two. Pertaining to impaired oxidative energy metabolism: in the mature brain, the recovery of cerebral NTP levels has been shown to correlate with the global ischemia duration. Specifically, ischemic durations less than $20 \mathrm{~min}$ result in full recovery of NTP levels, whereas durations 30 min or longer typically result in less than $80 \%$ recovery $(28,29)$. Several possible reasons for incomplete recovery of [NTP] exist. Reduced NTP levels may be due to limited $\mathrm{O}_{2}$ availability; however, this is unlikely since no inter-group differences in $\mathrm{CBF}$ and arterial $\mathrm{O}_{2}$ tension were observed. NTP regeneration may be limited by a loss of phosphates or a decrease in the adenosine pool size (28). The former is unlikely since no changes in [EPP] were observed. Although the possibility of the latter cannot be ruled out without quantifying the concentrations of AMP, ADP, and free adenosine, we suggest the most likely reason is impaired energy metabolism since we also observed a concurrent reduction in the ADC. Reduced ADC suggests the presence of intracellular cerebral edema, which is believed to reflect the inability of energy metabolism to restore cellular homeostasis (30). Lingwood et al. (31) showed that the amount of edema-as determined by impedance measurements-increased with insult severity in piglets after $\mathrm{HI}$.

Although the reduction in $\mathrm{CMRO}_{2}$ can be partially attributed to impaired energy metabolism, the changes in metabolite concentrations were relatively small. It is unlikely that increased anaerobic metabolism could maintain metabolite concentrations at preHI levels since a 4-to-5 fold increase would be needed to compensate for the $26 \%$ reduction in $\mathrm{CMRO}_{2}$.
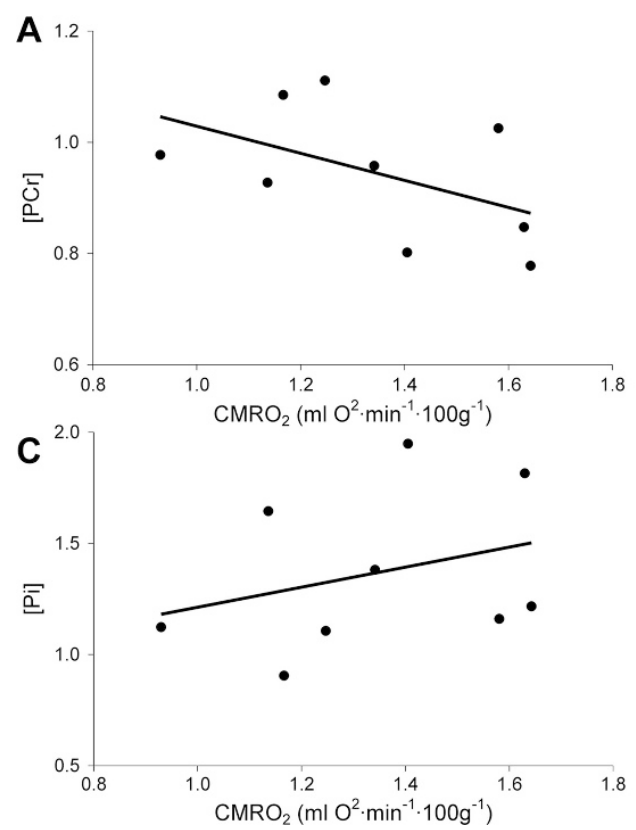
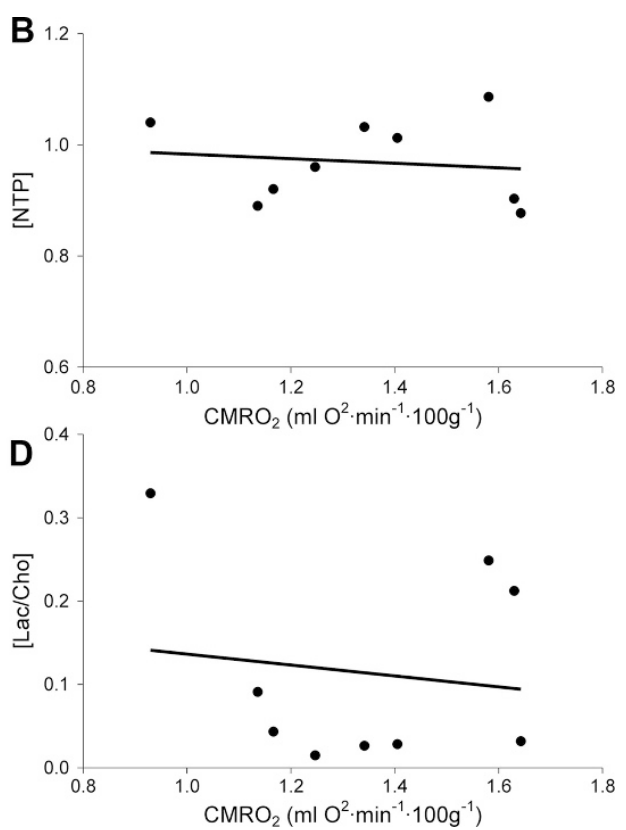

Figure 7. Regression of $\mathrm{CMRO}_{2}$ and each normalized metabolite concentration in the HI group averaged over the last 3 time points. The associated Pearson coefficients $(r)$ for each metabolite were $(A)$ [PCr], $r=$ $-0.50 ;(B)$ [NTP], $r=-0.13 ;(C)$ [Pi], $r=0.31$; and $(D)[\mathrm{Lac}] /[\mathrm{Cho}], r=-0.14$. None of the correlations reached statistical significance. The solid line represents the regression line. 
Increased glucose metabolism during the early recovery period has been observed in 7-d postnatal rats, but these changes were smaller than $50 \%$ (11). Increased glycolysis was also associated with comparable decreases in $[\mathrm{NTP}]$ and $[\mathrm{PCr}]$, which presumably reflects the inability of anaerobic metabolism to meet energy demands. In the present study, no reduction in [PCr] was observed and the decrease in [NTP] was only $8 \%$. Furthermore, no significant correlations were observed between $\mathrm{CMRO}_{2}$ and any of the phosphorus metabolites concentrations during the last $3 \mathrm{~h}$ of the recovery period; nor was there a correlation between $\mathrm{CMRO}_{2}$ and [Lac]/[Cho]. These results indicate that the $26 \%$ reduction in $\mathrm{CMRO}_{2}$ measured during the early recovery phase cannot be explained by impaired energy metabolism alone. Compared with the cited rat model study, the lack of evidence of a compensatory increase in glycolysis may be due to differences in insult severity or species. For example, reduced glucose metabolism was reported in fetal lambs subjected to HI near birth (32).

A likely contributing factor to lower $\mathrm{CMRO}_{2}$ values is reduced energy demands after $\mathrm{HI}$. Reduced oxidative metabolism with concurrent recovery of high-energy metabolites has been reported in models of global ischemia in the mature brain $(33,34)$. It has been postulated that these reductions reflect the suppression of energy requiring processes not essential to short-term cell survival (18). Although mechanisms leading to reduced energy demand are unclear, possible factors include reduced protein synthesis and inhibition of neuronal activity by disruptions in neurotransmitter metabolism (33). A decrease in oxidative metabolism that is independent of mitochondrial dysfunction might question the prognostic value of early $\mathrm{CMRO}_{2}$ measurements as metabolism could be equally suppressed in salvageable tissue and nonsalvageable tissue. By extending $\mathrm{CMRO}_{2}$ measurements out to $24 \mathrm{~h}$ postinsult, and varying insult duration, we recently demonstrated that $\mathrm{CMRO}_{2}$ measured as early as $8 \mathrm{~h}$ postHI can distinguish insult severities (unpublished data).

Limitations with this study includes the use of different regions of interest for the ${ }^{1} \mathrm{H}-\mathrm{MRS} / \mathrm{MRI}$ and ${ }^{31} \mathrm{P}-\mathrm{MRS}$ measurements. Deep gray matter was chosen for the ${ }^{1} \mathrm{H}-\mathrm{MRS}$ measurements, as this region is sensitive to $\mathrm{HI}$; however, regional differences in the response to $\mathrm{HI}$ could confound the comparison of ${ }^{1} \mathrm{H}$ - and ${ }^{31} \mathrm{P}-\mathrm{MRS}$ results. A second potential limitation is the use of vascular occluders as part of the hypoxic-ischemic injury. Although this model includes systemic hypoxia (16), the systemic effects are likely smaller than models that do not use vessel occlusion (35). It is possible that a more pronounced systemic injury would lead to a slower recovery of high-energy metabolite levels.

In summary, we have demonstrated how key elements of cerebral energy metabolism can be concurrently assessed noninvasively by combining NIRS and MRS. Using these combined methods, we speculate that reduced $\mathrm{CMRO}_{2}$ after $30 \mathrm{~min}$ of $\mathrm{HI}$ is because of a combination of two factors: impaired energy metabolism, as inferred by incomplete recovery of [NTP] and decreased ADC, and reduced energy demands, as evident by a nonsignificant increase in Lac and the lack of correlation between $\mathrm{CMRO}_{2}$ and metabolite concentrations. Regardless of the mechanisms leading to a reduction in oxygen utilization, these results suggest that measuring $\mathrm{CMRO}_{2}$ could be used as an early marker of $\mathrm{HI}$ before the development of secondary energy failure. The technique for measuring $\mathrm{CMRO}_{2}$ can be easily applied at the bedside of critically ill neonates and, thus, should be a clinically relevant method for early detection of neonatal brain injury.

Acknowledgments. We thank the assistance provided by Dominique Ouimet and Jennifer Hadaway.

\section{REFERENCES}

1. Ferriero DM 2004 Neonatal brain injury. N Engl J Med 351:1985-1995

2. du Plessis AJ, Volpe JJ 2002 Perinatal brain injury in the preterm and term newborn. Curr Opin Neurol 15:151-157

3. Volpe JJ 2001 Perinatal brain injury: from pathogenesis to neuroprotection. Ment Retard Dev Disabil Res Rev 7:56-64

4. Rutherford MA, Azzopardi D, Whitelaw A, Cowan F, Renowden S, Edwards AD, Thoresen M 2005 Mild hypothermia and the distribution of cerebral lesions in neonates with hypoxic-ischemic encephalopathy. Pediatrics 116:1001-1006

5. Cady EB 2001 Magnetic resonance spectroscopy in neonatal hypoxic-ischemic insults. Childs Nerv Syst 17:145-149

6. Azzopardi D, Wyatt JS, Cady EB, Delpy DT, Baudin J, Stewart AL, Hope PL, Hamilton PA, Reynolds EO 1989 Prognosis of newborn infants with hypoxicischemic brain injury assessed by phosphorus magnetic resonance spectroscopy. Pediatr Res 25:445-451

7. Roth SC, Baudin J, Cady E, Johal K, Townsend JP, Wyatt JS, Reynolds EO, Stewart AL 1997 Relation of deranged neonatal cerebral oxidative metabolism with neurodevelopmental outcome and head circumference at 4 years. Dev Med Child Neurol 39:718-725

8. Lorek A, Takei Y, Cady EB, Wyatt JS, Penrice J, Edwards AD, Peebles D, Wylezinska M, Owen-Reece H, Kirkbride V 1994 Delayed ("secondary") cerebral energy failure after acute hypoxia-ischemia in the newborn piglet: continuous 48-hour studies by phosphorus magnetic resonance spectroscopy. Pediatr Res 36:699-706

9. Penrice J, Lorek A, Cady EB, Amess PN, Wylezinska M, Cooper CE, D'Souza P, Brown GC, Kirkbride V, Edwards AD, Wyatt JS, Reynolds EO 1997 Proton magnetic resonance spectroscopy of the brain during acute hypoxia-ischemia and delayed cerebral energy failure in the newborn piglet. Pediatr Res 41:795-802

10. Palmer C, Brucklacher RM, Christensen MA, Vannucci RC 1990 Carbohydrate and energy metabolism during the evolution of hypoxic-ischemic brain damage in the immature rat. J Cereb Blood Flow Metab 10:227-235

11. Vannucci RC, Yager JY, Vannucci SJ 1994 Cerebral glucose and energy utilization during the evolution of hypoxic-ischemic brain damage in the immature rat. J Cereb Blood Flow Metab 14:279-288

12. Puka-Sundvall M, Wallin C, Gilland E, Hallin U, Wang X, Sandberg M, Karlsson J, Blomgren K, Hagberg H 2000 Impairment of mitochondrial respiration after cerebral hypoxia-ischemia in immature rats: relationship to activation of caspase-3 and neuronal injury. Brain Res Dev Brain Res 125:43-50

13. Hagberg H 2004 Mitochondrial impairment in the developing brain after hypoxiaischemia. J Bioenerg Biomembr 36:369-373

14. Brown DW, Picot PA, Naeini JG, Springett R, Delpy DT, Lee TY 2002 Quantitative near infrared spectroscopy measurement of cerebral hemodynamics in newborn piglets. Pediatr Res 51:564-570

15. Brown DW, Hadway J, Lee TY 2003 Near-infrared spectroscopy measurement of oxygen extraction fraction and cerebral metabolic rate of oxygen in newborn piglets. Pediatr Res 54:861-867

16. Tichauer KM, Brown DW, Hadway J, Lee TY, St Lawrence K 2006 Near-infrared spectroscopy measurements of cerebral blood flow and oxygen consumption following hypoxia-ischemia in newborn piglets. J Appl Physiol 100:850-857

17. Elwell CE, Henty JR, Leung TS, Austin T, Meek JH, Delpy DT, Wyatt JS 2005 Measurement of $\mathrm{CMRO}_{2}$ in neonates undergoing intensive care using near infrared spectroscopy. Adv Exp Med Biol 566:263-268

18. Sims NR, Zaidan E 1995 Biochemical changes associated with selective neuronal death following short-term cerebral ischemia. Int J Biochem Cell Biol 27:531-550

19. Matcher SJ, Cope M, Delpy DT 1994 Use of the water absorption spectrum to quantify tissue chromophore concentration changes in near-infrared spectroscopy. Phys Med Biol 39:177-196

20. Phelps ME, Huang SC, Hoffman EJ, Kuhl DE 1979 Validation of tomographic measurement of cerebral blood volume with C-11-labeled carboxyhemoglobin. J Nucl Med 20:328-334

21. Jensen JE, Drost DJ, Menon RS, Williamson PC 2002 In vivo brain (31)P-MRS: measuring the phospholipid resonances at 4 Tesla from small voxels. NMR Biomed 15:338-347

22. Bartha R, Drost DJ, Menon RS, Williamson PC 2000 Comparison of the quantification precision of human short echo time (1)H spectroscopy at 1.5 and 4.0 Tesla. Magn Reson Med 44:185-192 
23. Peeters-Scholte C, van den Tweel E, Ioroi T, Post I, Braun K, Veldhuis W, Nicolay K, Groenendaal F, van Bel F 2002 Pharmacological interventions in the newborn piglet in the first $24 \mathrm{~h}$ after hypoxia-ischemia. A hemodynamic and electrophysiological perspective. Exp Brain Res 147:200-208

24. Peeters-Scholte C, van den Tweel E, Groenendaal F, van Bel F 2004 Redox state of near infrared spectroscopy-measured cytochrome aa(3) correlates with delayed cerebral energy failure following perinatal hypoxia-ischemia in the newborn pig. Exp Brain Res 156:20-26

25. Chang YS, Park WS, Lee M, Kim KS, Shin SM, Choi JH 1999 Near infrared spectroscopic monitoring of secondary cerebral energy failure after transient global hypoxia-ischemia in the newborn piglet. Neurol Res 21:216-224

26. Cooper CE, Springett R 1997 Measurement of cytochrome oxidase and mitochondrial energetics by near-infrared spectroscopy. Philos Trans R Soc Lond B Biol Sci 352:669-676

27. Ioroi T, Peeters-Scholte C, Post I, Leusink C, Groenendaal F, van Bel F 2002 Changes in cerebral hemodynamics, regional oxygen saturation and amplitudeintegrated continuous EEG during hypoxia-ischemia and reperfusion in newborn piglets. Exp Brain Res 144:172-177

28. Nishijima MK, Koehler RC, Hurn PD, Eleff SM, Norris S, Jacobus WE, Traystman RJ 1989 Postischemic recovery rate of cerebral ATP, phosphocreatine, pH, and evoked potentials. Am J Physiol 257:H1860-H1870
29. Phillis JW, O’Regan MH, Estevez AY, Song D, VanderHeide SJ 1996 Cerebral energy metabolism during severe ischemia of varying duration and following reperfusion. J Neurochem 67:1525-1531

30. Olah L, Wecker S, Hoehn M 2000 Secondary deterioration of apparent diffusion coefficient after 1-hour transient focal cerebral ischemia in rats. J Cereb Blood Flow Metab 20:1474-1482

31. Lingwood BE, Dunster KR, Healy GN, Ward LC, Colditz PB 2003 Cerebral impedance and neurological outcome following a mild or severe hypoxic/ischemic episode in neonatal piglets. Brain Res 969:160-167

32. Thorngren-Jerneck K, Ley D, Hellstrom-Westas L, Hernandez-Andrade E, Lingman G, Ohlsson T, Oskarsson G, Pesonen E, Sandell A, Strand SE, Werner O, Marsal K 2001 Reduced postnatal cerebral glucose metabolism measured by PET after asphyxia in near term fetal lambs. J Neurosci Res 66:844-850

33. Pulsinelli WA, Levy DE, Duffy TE 1982 Regional cerebral blood flow and glucose metabolism following transient forebrain ischemia. Ann Neurol 11:499-502

34. Steen PA, Milde JH, Michenfelder JD 1978 Cerebral metabolic and vascular effects of barbiturate therapy following complete global ischemia. J Neurochem 31:1317-1324

35. Thoresen M, Haaland K, Loberg EM, Whitelaw A, Apricena F, Hanko E, Steen PA 1996 A piglet survival model of posthypoxic encephalopathy. Pediatr Res 40:738-748 